\title{
C\&T e I para a produção agropecuária brasileira: mensurando e qualificando gastos públicos
}

\author{
Mário Otávio Batalha ${ }^{1}$ \\ Gisele de Lorena Diniz Chaves ${ }^{2}$ \\ Hildo Meirelles de Souza Filho ${ }^{3}$
}

Resumo: Existem poucas pesquisas no Brasil que abordam a questão da quantificação e da qualificação dos gastos públicos em Ciência, Tecnologia e Inovação (C\&T e I) voltados para a produção agropecuária nacional. Considerando esta lacuna na bibliografia e que informações nesta área são importantes para tomadores de decisão públicos e privados envolvidos com o tema, este artigo apresenta um diagnóstico inovador destes gastos no Brasil. Para tanto, foram analisados os investimentos realizados por 48 instituições de apoio e de pesquisa brasileiras, cobrindo praticamente o universo de agências e institutos de pesquisa estaduais e federais com atuação no setor agropecuário, além de instituições de pesquisa sem fins lucrativos. Os resultados apontam o papel preponderante da Embrapa no Sistema Nacional de Pesquisa Agropecuária, bem como destaca algumas lacunas e entraves ao desenvolvimento científico e tecnológico voltado para este setor. Os futuros investimentos nesta área poderão ser ponderados a luz dos resultados da pesquisa apresentada neste artigo.

${ }^{1}$ Professor e pesquisador do Programa de Pós-graduação em Engenharia de Produção da Universidade Federal de São Carlos. Coordenador do Grupo de Estudos e Pesquisas Agroindustriais da UFSCar. E-mail: dmob@power.ufscar.br

${ }^{2}$ Doutora pelo Programa de Pós-graduação em Engenharia de Produção da Universidade Federal de São Carlos. Pesquisadora do Grupo de Estudos e Pesquisas Agroindustriais da UFSCar. E-mail: gisele@dep.ufscar.br

${ }^{3}$ Professor e pesquisador do Programa de Pós-graduação em Engenharia de Produção da Universidade Federal de São Carlos. Pesquisador do Grupo de Estudos e Pesquisas Agroindustriais da UFSCar. E-mail: hildo@dep.ufscar.br 
124 - C\&T e I para a produção agropecuária brasileira: mensurando e qualificando gastos públicos

Palavras-chaves: Agronegócio; inovação tecnológica; tecnologia.

Classificação JEL: Q, Q16.

Abstract: Few researches in Brazil have undertaken the issue of quantification and qualification of public expenditure in SET and Innovation devoted to agriculture and livestock. This paper presents an innovative evaluation and provides inedited information for public and private decision makers. Expenditure undertook by 48 Brazilian research organizations was evaluated. This set of organizations comprised the universe of federal and state institutes and agencies, as well as some other non-profit organizations, which gave support to research in agriculture and livestock. The results showed that the role played by Embrapa is of primary importance to the National System of Agricultural Research. Some deficiencies and barriers to scientific and technological development in this sector are also revealed. Expenditure allocation in this area should consider the results presented in this paper.

Key-words: Agribusiness; technological innovation; technology.

JEL Classification: Q, Q16.

\section{Introdução}

O Brasil tem tido iniciativas promissoras para a definição, tratamento, organização e divulgação de informações e indicadores voltados às atividades de Ciência, Tecnologia e Inovação (C\&T e I) e de Pesquisa e Desenvolvimento (P\&D). Apesar de estratégico para instituições públicas e privadas, esse tipo de informação ainda é difícil de ser produzido e obtido no País. Esta dificuldade é ainda maior quando se procuram informações e pesquisas em áreas voltadas para os diversos setores econômicos e produtivos que compõem o agronegócio.

No Brasil, as iniciativas para analisar as atividades de C\&T e I vêm encontrando obstáculos e dificuldades. Entre eles, pode-se citar a pouca tradição do Brasil nesta área, a ausência de periodicidade definida para as pesquisas e a heterogeneidade das metodologias utilizadas para levantamento e tratamento dos dados. Estas dificuldades impedem a construção de séries de dados mais robustos e passíveis de serem 
utilizadas para a elaboração de estudos e análises que possam ser empregadas no planejamento de políticas públicas e privadas de C\&T e I.

Dentre os principais trabalhos realizados nos últimos anos no Brasil em relação a investimentos em C\&T e I destaca-se a Pesquisa Industrial de Inovação Tecnológica (Pintec), conduzida pelo Instituto Brasileiro de Geografia e Estatística (IBGE) e pela Financiadora de Estudos e Projetos (Finep), com o objetivo de pesquisar empresas industriais e de serviços de alta tecnologia. A Pintec possui levantamentos disponíveis na área de gastos privados em P\&D para os anos de 2000, 2003 e 2005 (Pintec, 2008). Deve-se destacar, ainda no âmbito dos investimentos privados em C\&T e I, a criação do Diretório da Pesquisa Privada (DPP), que, a partir de uma iniciativa da Finep, levantou informações e construiu uma base de dados que abrange mais de 650 empresas e ONG's (Finep, 2008). O objetivo do DPP foi o de subsidiar a reflexão e auxiliar a tomada de decisões pelos organismos nacionais de fomento, sobretudo a Finep e o Ministério de Ciência e Tecnologia.

Já em 1995, Meyer-Stamer apontavam que a falta de um sistema de inovação e a falta de interação entre as instituições de pesquisa, universidades e empresas fragilizavam as políticas tecnológicas executadas no País. Desta forma, no sentido de fornecer incentivos à inovação e à pesquisa científica e tecnológica no Brasil, foi promulgada a Lei de Inovação (Lei n⿳o 10.973/2004) e sua regulamentação por meio do Decreto $n^{\mathbf{0}}$ 5.563 , em outubro de 2005. Deve-se ressaltar, contudo, que o instrumento da Lei necessita ser aperfeiçoado em alguns pontos, tais como a proteção do conhecimento, licenciamento e transferência de tecnologia e parceria público-privada, evitando a burocratização. Assim, é importante que o País possa contar com informações que subsidiem ações nesta área.

Enquanto existem alguns estudos - embora com deficiências - sobre gastos privados em C\&T e I ligados aos insumos agropecuários no Brasil, a literatura sobre a avaliação desses gastos públicos em C\&T e I em insumos agropecuários é praticamente inexistente. Visando ampliar a disponibilidade de informações em C\&T e I nesses setores econômicos, este artigo apresenta um diagnóstico inédito dos gastos públicos em C\&T e I relacionados à produção de insumos para a agropecuária brasileira.

Este artigo está estruturado em seis seções. Além desta introdução, o artigo traz, na sua segunda seção, alguns conceitos de C\&T e I fundamentais para uma avaliação de gastos dessa natureza vinculados à produção agropecuária. Na seção seguinte, é identificado o papel do setor 
público na geração de inovações para a produção agropecuária brasileira. A metodologia utilizada nesta pesquisa é apresentada em seção subseqüente. Os resultados encontrados neste trabalho encontram-se na seção cinco e, as considerações finais, ao final do artigo.

\section{Alguns aspectos conceituais em C\&T e I para a produção agropecuária}

Essa seção tem como objetivo discutir três aspectos fundamentais em pesquisas que visam levantar gastos em $C \& T$ e I destinados à produção agropecuária. $\mathrm{O}$ primeiro diz respeito à própria definição de inovação tecnológica; o segundo está relacionado com a identificação das fontes de inovação para a produção agropecuária e o terceiro procura identificar o que pode ser considerado como gasto em C\&T e I.

No Manual de Oslo-2 (OCDE, 1996), inovação tecnológica encontra-se dividida em duas categorias: inovação tecnológica de produto e inovação tecnológica de processo. A inovação de produto pode, ainda, ser subdividida em novos produtos e produtos melhorados. As definições para esses três tipos de inovações são as seguintes:

- Um produto tecnologicamente novo é aquele cujas características tecnológicas ou usos pretendidos diferem significativamente dos produtos previamente produzidos. Tais inovações podem envolver tecnologias radicalmente novas e podem ser baseadas na combinação de tecnologias existentes ou derivadas do uso de novos conhecimentos.

- Um produto tecnologicamente melhorado é aquele cujo desempenho foi significativamente aperfeiçoado ou atualizado. Um produto pode ser melhorado por meio do uso de componentes ou materiais de alta-performance; ou um produto complexo que consiste de um número de subsistemas técnicos integrados pode ser melhorado por mudanças parciais em um dos subsistemas.

- Inovação tecnológica de processo é a adoção de métodos de produção tecnologicamente novos ou significativamente melhorados, incluindo métodos de apresentação de produto. Esses métodos podem envolver mudanças em equipamentos, ou organização da produção, ou a combinação dessas mudanças, e podem ser derivados do uso de novos conhecimentos. 
De forma geral, existe um consenso na literatura econômica que estuda o processo de inovações tecnológicas e mudanças técnicas, de classificar a agricultura como um setor dominado pelos fornecedores. $\mathrm{Na}$ realidade, a agricultura não apresenta uma única dinâmica inovadora. Ela possui diversas fontes de inovações que apresentam importantes diferenças quanto à sua origem disciplinar e estratégica. Possas, Salles-Filho e Silveira (1996) sugerem que essas fontes de inovação para a agricultura podem ser classificadas da seguinte forma:

(i) Fontes privadas de organizações industriais de mercado: 0 objetivo dessas unidades é produzir e vender produtos intermediários e máquinas para os mercados agrícolas; entre elas estão as indústrias de máquinas e equipamentos, fertilizantes, defensivos, etc.

(ii) Fontes públicas institucionais: objetivam ampliar o conhecimento científico por meio de atividades de pesquisa básica, desenvolvimento e melhoramento de tecnologias e produtos agrícolas e o estabelecimento e transferência de práticas agrícolas mais eficientes.

(iii) Fontes privadas vinculadas à agroindústria: as indústrias à jusante geram e difundem novas tecnologias, interferindo direta ou indiretamente na produção dos produtos primários, com o principal intuito de beneficiar os estágios subseqüentes de processamento industrial.

(iv) Fontes privadas, organizadas coletivamente e sem fins lucrativos: são entidades que visam o desenvolvimento e transferência (remunerada ou não) de insumos e práticas agrícolas. Em alguns mercados específicos possuem uma ampla capacidade de influenciar os padrões competitivos.

(v) Fontes privadas relacionadas a serviços de suporte para a atividade agrícola: em geral, importante papel de disseminadores de tecnologia, baseando-se em habilidades específicas e na quantidade e qualidade das informações que conseguem processar.

(vi) Unidades de produção agrícola: incorporam o novo conhecimento por meio de um processo de aprendizado, que pode culminar em inovações. O conhecimento tácito desenvolvido pelos agricultores afeta, de forma marcante, o grau de cumulatividade e a capacidade tecnológica dos mesmos. 
Essas diferentes fontes de inovação tecnológica para a agricultura estão distribuídas por todas as classes taxonômicas elaboradas por Pavitt (1984) e Bell e Pavitt (1993), de forma a caracterizar os setores e, por conseguinte, as suas firmas, de acordo com o comportamento inovador. Os autores ilustram esta afirmação com exemplos: as indústrias de sementes e defensivos podem ser classificadas como intensivas em ciência ('science-based'); a indústria de fertilizantes, como intensiva em escala ('scale-intensive'); a de máquinas e equipamentos, em fornecedores especializados ('specialized-supplier'); a indústria de alimentos, caracterizando-se por ser dominada pelos fornecedores ('supplier-dominated') ou as intensivas em escala ('scale-intensive') e, as firmas que fornecem serviços de suporte para a atividade agrícola, como intensivas em informação ('information-intensive').

Portanto, as atividades de produção agropecuária apresentam um regime tecnológico dominado por empresas à montante que, juntamente com as instituições públicas de pesquisa, formam os seus dois principais 'pilares' em termos de gastos em C\&T e I. Esta constatação permitiu estabelecer o foco do presente artigo em um desses pilares: os gastos públicos em C\&T e I.

A obtenção de dados sobre esse tipo de gasto não é tarefa trivial. No Manual de Oslo, adota-se um enfoque baseado no tema, dividindo-se os gastos em inovação em categorias: pesquisa, desenvolvimento experimental, construção e design, patentes e licenças, preparação da produção de novos produtos, inovação de processos de produção e inovação de processos de gestão. A coleta junto aos agentes geradores de inovações, contudo, pode levar a grandes frustrações, visto que muitas vezes é difícil determinar de forma consistente a diferença entre novo e melhorado. Outra dificuldade decorre da existência de uma tensão entre dados que seriam mais úteis sob a perspectiva dos formuladores de política tecnológica e dados que as firmas são capazes ou estão dispostas a revelar.

Um dos maiores problemas na obtenção de dados dessa natureza encontra-se no fato de que eles não são facilmente distinguíveis dos gastos relacionados com atividades de rotina. Por exemplo, em muitas firmas, o responsável por pesquisa também dedica parte de seu tempo no desenvolvimento de produtos, que refletem mera variação de estilo, o que não poderia ser considerado propriamente uma inovação de produto. Gastos com a planta industrial e equipamentos nem sempre são 
facilmente segregados em gastos em novos produtos (especialmente gastos em produtos tecnologicamente novos) e gastos com a expansão da produção de produtos já existentes. Para solucionar o problema, Oslo-2 recomenda que se questione se os dados fornecidos são grosseiramente estimados ou se são resultado de algum cálculo de maior precisão. Isso pode induzir muitas firmas a responderem que são estimativas grosseiras, mas, por outro lado, aumenta a taxa de retorno de respostas.

Na CIS-2 (community innovation survey) existe uma seção solicitando às firmas que desagreguem os custos com inovações, segundo as seguintes categorias:

- Pesquisa e desenvolvimento experimental dentro da empresa

- Aquisição de serviços de P\&D

- Aquisição de máquinas e equipamentos relacionados à inovação de produto ou de processo

- Aquisição de outras tecnologias externas, relacionadas à inovação de produto ou de processo

- Desenho industrial, outras preparações para a produção de produtos tecnologicamente novos ou melhorados

- Treinamento diretamente relacionado com inovações tecnológicas

- Introdução no mercado de inovações tecnológicas

Com a finalidade de se avaliar o perfil da atividade inovativa, deve-se investigar aspectos relativos à estrutura de P\&D dentro das firmas. Pode-se questionar sobre a porcentagem de P\&D nos gastos com uma unidade central de pesquisa, ao invés de se questionar sobre gastos em divisões de produção. Outras questões envolvem o montante de tempo que o pessoal de $\mathrm{P} \& D$ dispensa para um número de atividades, tais como reuniões com pessoal de marketing ou produção, participação em conferências, educação adicional, etc. Ainda, pode-se questionar o grau de contratação de $\mathrm{P} \& \mathrm{D}$ fora das fronteiras da firma ou a participação conjunta em atividades de P\&D com universidades, laboratórios governamentais, ou outras empresas.

Uma vez que P\&D representa apenas uma fração limitada dos gastos com inovação, devem-se avaliar demais fatores, como investimento em equipamentos e maquinaria e design, visto que estes podem representar a maior parcela dos gastos das empresas com inovação.

Indicadores tradicionais de inovação são baseados em dados públicos para evitar o problema de sigilo das empresas. Neste conjunto, estão 
incluídos dados publicamente disponíveis sobre patentes, publicações científicas e o emprego de cientistas e engenheiros. Dados sobre gastos em P\&D fornecem apenas um indicador de investimento total em um número limitado de atividades em inovações tecnológicas.

\section{O papel de algumas instituições públicas em C\&T e I para a produção agropecuária no Brasil}

O governo federal participa do sistema de pesquisa agropecuária brasileiro, diretamente, por meio de três agências: a Embrapa (Empresa Brasileira de Pesquisa Agropecuária), a Ceplac (Cepec - Centro de Pesquisa de Cacau) e o Ibama (Instituto Nacional de Recursos Naturais e Meio Ambiente). Além dessas, há agências federais de fomento não voltadas exclusivamente para a produção agropecuária, destacando-se o $\mathrm{CNPq}$ e a Finep. A Embrapa é a principal organização de pesquisa agropecuária nacional, sendo controlada pelo Ministério da Agricultura e Abastecimento, assim como a Ceplac, que fiscaliza o Cepec. Já o Ibama é vinculado ao Ministério do Meio Ambiente, tendo as suas ações voltadas prioritariamente para a fiscalização das leis ambientais.

No final da década de 90, existiam cinco importantes instituições sem fins lucrativos envolvidas em pesquisa agropecuária no Brasil: a Copersucar (Cooperativa de Produtores de Cana-de-açúcar, Açúcar e Álcool do Estado de São Paulo), o Fundecitrus (Fundo de Defesa da Citricultura), o Irga (Instituto Rio Grandense do Arroz), o Fundacep (Fundação Centro de Experimentação e Pesquisa em Trigo) e Coodetec (Cooperativa Central Agropecuária de Desenvolvimento Tecnológico e Econômico) (BEINTEMA et al, 2001).

Segundo Beintema et al. (2001), a participação efetiva dos governos estaduais em pesquisas agropecuárias é bastante heterogênea. No final da década de 90, sete estados brasileiros não possuíam institutos ou agências de pesquisas agropecuárias. Dos dezesseis estados da União que contavam com agências estaduais de pesquisa voltadas para a produção agropecuária, quinze tinham apenas uma agência, sendo que o estado de São Paulo era o único da Federação a possuir mais de uma agência (entre elas, o Instituto Agronômico de Campinas - IAC, o Instituto Biológico - IB, o Instituto de Tecnologia de Alimentos - ITAL, o Instituto de Zootecnia IZ, o Instituto de Pesca - IP e o Instituto de Economia Agrícola - IEA). Os 
autores ainda ressaltavam que as agências pertencentes aos governos estaduais do Ceará e do Maranhão foram fechadas nos anos de 1998 e 1999 e, no Tocantins, a pesquisa agropecuária estava sob responsabilidade da Faculdade de Agronomia da Universidade de Tocantins.

Beintema et al. (2001), apesar de relatarem a complexidade do sistema brasileiro de pesquisa agropecuária, com a participação de diversas agências federais, estaduais, de ensino superior, instituições sem fins lucrativos e companhias privadas engajadas nesse esforço de pesquisa, concluíram que "a pesquisa agropecuária brasileira ainda é, predominantemente, uma atribuição do setor público". Esta afirmação é corroborada pelas estimativas obtidas no estudo destes autores, as quais demonstraram que, para o ano de 1996, 79\% dos gastos em pesquisas agropecuárias foram efetivados por agências governamentais. No mesmo estudo, os autores estimaram que $72 \%$ dos gastos em pesquisa pública agropecuária foram de responsabilidade da Embrapa, o que ressalta a importância relativa desta instituição em relação às outras agências públicas, sobretudo estaduais e de ensino superior (BEINTEMA et al, 2001).

O relatório elaborado pelo International Food Policy Research Institute (IFPRI) em colaboração com a Universidade da Califórnia (2001) mostra que a Embrapa teve um papel decisivo nos resultados que vêm sendo obtidos na agropecuária brasileira. Esse papel é compartilhado com outras instituições públicas e privadas, as quais "atuam em parceria ou isoladamente na pesquisa agropecuária" (IFPRI, 2001, p.20).

\section{Metodologia da pesquisa}

A pesquisa na qual este artigo está baseado se caracteriza por ser do tipo "descritivo-quantitativa", já que o objetivo deste estudo foi o de identificar e fazer um diagnóstico dos gastos públicos em C\&T e I voltados para a produção de insumos agropecuários no Brasil. Os dados foram coletados por meio de uma survey que teve como instrumento de coleta questionários enviado por correio.

A amostra da pesquisa compreendeu 48 instituições, cobrindo praticamente o universo de agências e institutos de pesquisa estaduais e federais, além de instituições de pesquisa sem fins lucrativos, também conhecidas por pertencerem ao terceiro setor. No âmbito dos estados, encontram-se as Agências de Fomento ou Fundações de Apoio à Pesquisa (FAP's) e Institutos Públicos de Pesquisa Agropecuária (IP's). No âmbito 
federal, estão o CNPq, a FINEP (ANF's) e a Embrapa. O Anexo apresenta a lista dessas instituições.

Praticamente todas as instituições participaram da pesquisa. Somente a Fapeal (AL) e a Funcap (CE) não enviaram as informações solicitadas. O Instituto de Zootecnia (IZ), o Idaterra e a Apta/Regional se recusaram a fornecer os dados solicitados. Outras fundações afirmaram não ter realizado financiamentos para pesquisa nestas áreas no ano investigado pela pesquisa (Ipes - ES, Fapesq, Fapep, Fapepi - PI, Fapema - MA).

A cada uma destas instituições foi solicitado o preenchimento de um questionário, no qual deveriam ser informados gastos em projetos relacionados aos insumos para a produção agropecuária e os seus diversos desdobramentos. Vale notar que o estabelecimento do foco em insumos segue a constatação, apresentada na seção 2 , de que as inovações para essas atividades são majoritariamente geradas em atividades a montante da produção agropecuária. Nesse sentido, indicaram-se explicitamente as classes de produtos sujeitos à inovação: sementes/mudas, maquinários/equipamentos agrícolas e para a pecuária, defensivos agrícolas, genética animal, genética vegetal, defensivos animais, fertilizantes e alimentação animal.

Os gastos informados restringiram-se apenas aos dispêndios orçamentários das instituições no ano de 2004. Foi solicitado que os dispêndios totais fossem discriminados da seguinte forma:

1. custeio: desdobrado em gastos com pessoal, materiais, viagens, treinamento e outros;

2. capital: desdobrado em gastos com compra e/ou aluguel de máquinas e equipamentos para laboratórios e experimentos, instalações e outros.

Era também objetivo da pesquisa identificar esses gastos segundo o tipo de atividade a que se destinava a inovação. Entretanto, teste preliminar do questionário apontou que a maioria das instituições teria dificuldades em obter informação precisa a partir de seus registros. No caso dos IP's, essa dificuldade foi menor, dado que as atividades da maioria deles são orientadas e classificadas segundo os vários produtos agropecuários. No caso das agências federais, CNPq e Finep, e estaduais de fomento, FAP's, a dificuldades foi maior, devido à orientação mais abrangente.

Para solucionar o problema, embora ocorrendo em inevitáveis imprecisões, foram adotadas duas soluções. Aos IP's, foi solicitada uma 
estimativa, ainda que grosseira, mas baseada nos registros disponíveis, da distribuição do gasto total segundo as principais atividades agropecuárias atendidas. Dessa forma, obteve-se informação sobre a distribuição dos gastos para as seguintes atividades: Carne Bovina e Bubalinos; Carne Suína e de Frango; Leite; Caprinos e Ovinos; Aqüicultura; Eqüinocultura; Outras Atividades da Pecuária, tais como Pequenos Animais (Coelho, Apicultura, etc.), Alimentação Animal (Pastagens/Forrageiras e Ração Animal, Palma, Sorgo e Milheto), Sanidade e Doença Animal; Frutas (incluindo Castanha do Brasil, Cupuaçu, Frutas Nativas do Cerrado); Olerícolas/Hortícolas, Flores e Ornamentais, Plantas Medicinais; Café; Soja e Milho; Açúcar e Álcool; Citros; Arroz; Algodão; Trigo; Papel e Celulose; Fumo; Feijão; Mandioca e Inhame; Seringueira; Outros Produtos Agrícolas: incluindo Matéria Prima (urucum/mamona), Mamona, Guaiana e Pupunha; Agricultura Orgânica; Sistemas Agrosustentáveis e Recursos Ambientais (incluindo Desenvolvimento Sustentável, Desenvolvimento, Diversificação Agropecuária, Agroecologia, Recursos Florestais, Pesquisa temática, Recursos Hídricos); Sistemas de Produção (incluindo Manejo Solos e Nutrição de Plantas, Sistemas Produção e Produção Sementes e Mudas); Agrometeorologia; Controle Biológico, Fitopatologia e Pragas; Biotecnologia e Melhoramento Genético; e Outros (incluindo Agroindústria, Planejamento Inst. e Recursos Humanos, Bioativas e Outros).

No caso das FAPs, CNPq e Finep, coube aos pesquisadores do projeto, a partir do título e das palavras-chaves anotadas nas planilhas de investimentos em projetos disponibilizadas por estas Instituições, alocar os investimentos segundo as várias atividades agropecuárias. Além disso, deve-se ressaltar que o valor informado pelo $\mathrm{CNPq}$ não inclui o valor de bolsas de mestrado, doutorado, produtividade em pesquisa, apoio técnico e outras. Desta forma, o valor informado pelo CNPq está certamente subestimado.

Para as FAP's, solicitou-se, ainda, que os recursos financeiros oriundos de instituições federais não fossem considerados. Buscava-se com essa providência eliminar problemas de "dupla contagem" nos investimentos realizados. Assim, as FAP's deveriam assinalar somente os financiamentos realizados com recursos próprios ${ }^{4}$.

A Embrapa forneceu o orçamento executado de cada um dos seus 40 Centros de Pesquisa, não incluindo os projetos financiados no âmbito dos

\footnotetext{
${ }^{4}$ Os dados enviados pela Fapeam não foram utilizados nesta pesquisa, visto que esta fundação não excluiu a parcela referente aos recursos federais repassados à instituição.
} 
seus macroprogramas de pesquisa. Esses orçamentos foram alocados segundo três métodos diferentes. Nos casos de unidades vinculadas aos produtos, como a Embrapa Soja, o orçamento total da unidade foi alocado como gasto na respectiva atividade agropecuária. No caso de unidades que abrangiam a área de tecnologia e pós-porteira, como a Embrapa Instrumentação Agropecuária, o orçamento total da unidade foi alocado como um gasto em Outras Atividades. No caso destas unidades, sabia-se que o orçamento cobria gastos em diversas áreas de pesquisa. Embora fosse possível identificar quais eram essas áreas e a que atividades agropecuárias elas estavam vinculadas, não havia informação sobre o valor alocado a cada uma. Para solucionar o problema e evitar a perda de informação, o orçamento dessas unidades foi distribuído igualmente entre as respectivas atividades agropecuárias diretamente vinculadas às áreas de pesquisa relacionadas nos sites das Unidades em questão.

Em pesquisa realizada por Beintema et al (2001), ocorreram muitas dificuldades na coleta e no tratamento das informações relacionadas à participação das universidades e Faculdades, principalmente quanto ao rateio dos dispêndios realizados em comparação com o real volume de recursos aportados exclusivamente por estas entidades nas pesquisas agropecuárias no País. Portanto, as universidades e instituições de ensino não estão incluídas diretamente na amostra investigada para evitar erros de dupla contagem dos investimentos.

\section{Apresentação, análise e discussão dos resultados}

Os dados coletados e analisados permitiram uma detalhada descrição da atividade dos gastos em C\&T e I voltados à produção de insumos agropecuários e para a produção agropecuária propriamente dita, tanto em termos da natureza das inovações quanto do volume de investimento e atividades produtivas beneficiadas.

\subsection{Caracterização dos gastos públicos em C\&T e I para a produção agropecuária}

Nesta seção, são apresentados os resultados encontrados na pesquisa realizada junto aos vários agentes. Após análise dos dados, foi possível identificar um gasto total para o setor de mais de $\mathrm{R} \$ 1,2$ bilhão de reais em C\&T e I pelo setor público, como mostra a Tabela 1. 
Tabela 1. Total de gastos públicos em C\&T e I para o setor de insumos agropecuários em 2004

\begin{tabular}{lcc}
\hline Agregados & Gastos (em milhões de reais) & Porcentagem \\
\hline ANF's & 33,645 & $2,8 \%$ \\
FAP's & 24,727 & $2,0 \%$ \\
IP's & 224,081 & $18,4 \%$ \\
Embrapa & 932,433 & $76,8 \%$ \\
TOTAL & $1.214,886$ & $100,0 \%$ \\
\hline
\end{tabular}

Fonte: Resultados da pesquisa.

A importância da Embrapa para as pesquisas neste setor é inconteste. Somente ela participou com 76,8\% dos gastos públicos no ano de 2004 .

Do total gasto pelas Agências Nacionais de Fomento, $79,4 \%$ é oriundo de recursos da Finep e, 20,6\%, do CNPq. Vale ressaltar que, 59,6\% do total gasto pela Finep no ano analisado foram provenientes de apenas um projeto vinculado à produção de carnes suína e de frango.

A Figura 1 traz a participação de cada uma das Fundações Estaduais de Apoio à Pesquisa para a constituição dos gastos totais deste grupo. Destaca-se a participação da Fapesp, com 47,6\% dos gastos de todas as FAP's. Em seguida, os gastos da Fapemat representaram 11,5\% do total dos gastos das FAP's em 2004, os da Fapergs, 10,4\% e os da Fundação Araucária, 8,5\%.

Figura 1. Distribuição dos gastos das Fundações de Apoio à Pesquisa em C\&T e I para a produção agropecuária no ano de 2004.

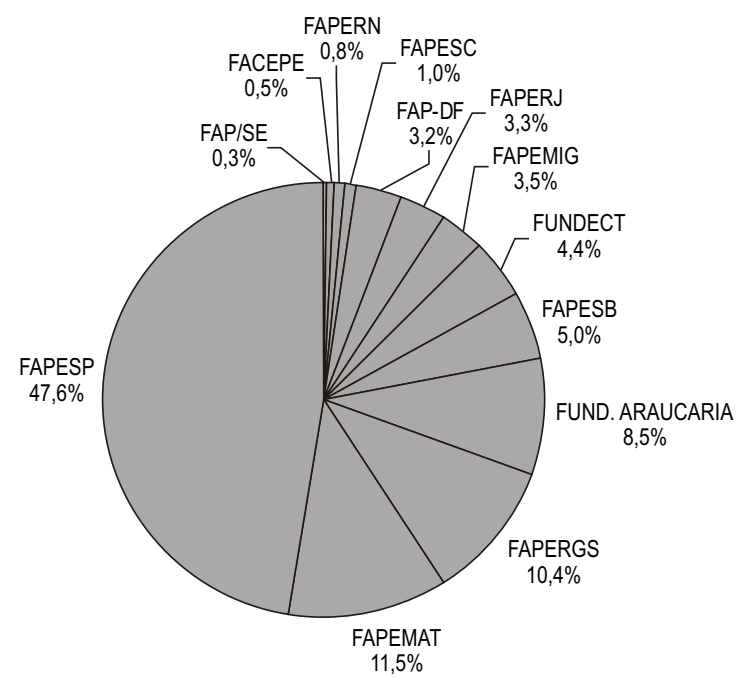

Fonte: Resultados da pesquisa. 
A Figura 2 traz a distribuição dos gastos dos Institutos de Pesquisa em C\&T e I em 2004. Pode-se observar que esta distribuição é mais equilibrada que a dos gastos das FAP's. Os institutos com maior volume de gastos são, por ordem decrescente, a Epagri-SC, com 24,1\% do total de gastos dos IP's; a Epamig-MG, com 16,7\%; o Iapar-PR, com 11,7\%; o IAC-SP, com $9,4 \%$ e o Pesagro-RJ com $8,2 \%$.

Os gastos públicos com C\&T e I foram alocados em diversas cadeias produtivas, de acordo com a importância de cada cadeia para o instituto de pesquisa. A Tabela 2 traz os valores despendidos por cada agregado do setor público e por áreas/cadeias. Pode-se observar que algumas cadeias possuem um volume de investimentos superior, como soja e milho, frutas, carne bovina e de bubalinos, carne suína e de frango, e leite.

Figura 2. Distribuição dos gastos dos Institutos de Pesquisa em C\&T e I para a produção agropecuária no ano de 2004.

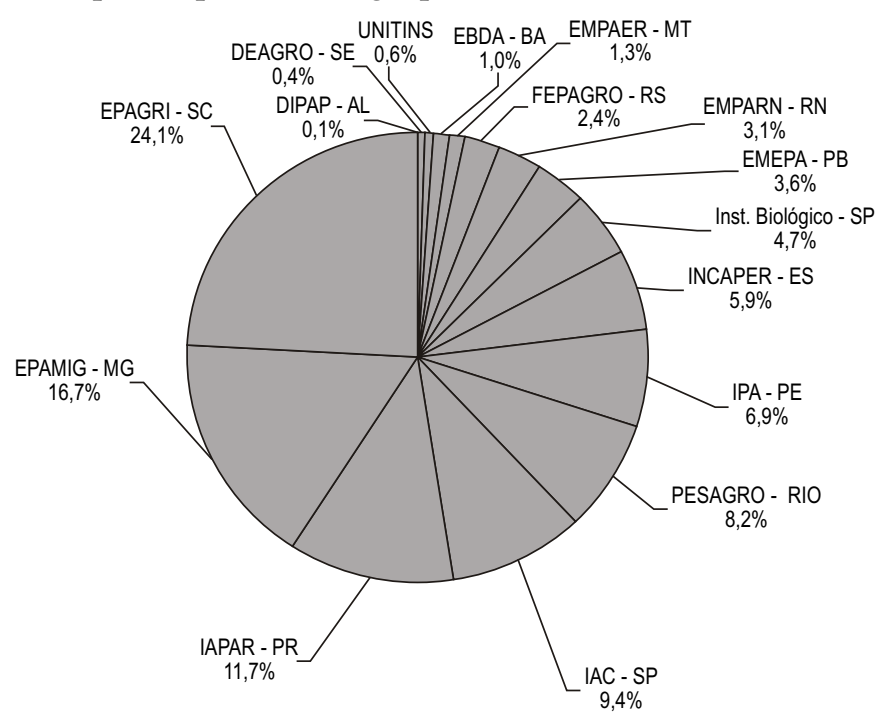

Fonte: Resultados da pesquisa.

Outra área de destaque é a de Sistemas Agrosustentáveis e Recursos Ambientais. Isso se pode justificar pelo fato que, nesta área, foram incorporados os gastos referentes a projetos voltados ao desenvolvimento sustentável de uma região, sendo muito influenciado pelos gastos da Embrapa. Outras áreas que também se destacaram como recebedoras de recursos foram: Sistemas de Produção e Manejo de Solos, 
Controle Biológico, Fitopatologia e Pragas e Biotecnologia e Melhoramento Genético.

Como a Embrapa representa a maior parte destes investimentos, é conveniente analisar separadamente os gastos dos demais institutos de pesquisa, no sentido de conhecer a orientação destes para cadeias específicas. Em 2004, as Agências Nacionais de Fomento deram maior destaque às Cadeias Suína e de Frango, por meio de um projeto financiado pela Finep para melhoria da genética de suínos.

Os gastos das Fundações de Apoio à Pesquisa foram equilibrados entre as diversas cadeias. Os maiores investimentos ocorreram em Carne Bovina e Bubalinos, Sistemas Agrosustentáveis e Recursos Ambientais, Outros Pecuária, Sistemas de Produção e Manejo de Solos, Aqüicultura e Frutas. Por sua vez, os Institutos de Pesquisa deram maior destaque às pesquisas em Frutas e Café, Sistemas Agrosustentáveis e Recursos Ambientais. Os gastos dos IP's, assim como das FAP's, foram equilibrados, sem grandes contrastes.

Tabela 2. Gastos públicos em C\&T e I subdivididos por áreas/cadeias em 2004 (em R \$ mil).

\begin{tabular}{|c|c|c|c|c|c|c|}
\hline & ANF's & FAP's & IP's & Embrapa & TOTAL & $\begin{array}{c}\% \text { dos } \\
\text { Investimentos } \\
\text { totais } \\
\end{array}$ \\
\hline $\begin{array}{l}\text { Carne Bovina } \\
\text { e de Bubalinos }\end{array}$ & 307,8 & $2.223,80$ & $12.649,80$ & $47.542,80$ & $62.724,30$ & 5,16 \\
\hline $\begin{array}{l}\text { Carne Suína } \\
\text { e de Frango }\end{array}$ & $15.917,70$ & $1.292,80$ & $4.960,70$ & $20.521,80$ & $42.693,00$ & 3,51 \\
\hline Leite & 146 & 665,1 & $14.363,00$ & $41.468,40$ & $56.642,40$ & 4,66 \\
\hline $\begin{array}{l}\text { Caprinos } \\
\text { e Ovinos }\end{array}$ & 89,5 & 577,8 & $3.460,80$ & $27.317,00$ & $31.445,10$ & 2,59 \\
\hline Aqüicultura & $2.190,00$ & $1.557,40$ & $8.020,80$ & $10.926,20$ & $22.694,40$ & 1,87 \\
\hline Eqüinocultura & - & 547,8 & - & $2.353,20$ & $2.901,00$ & 0,24 \\
\hline Outros Pecuária & $2.599,90$ & $1.940,20$ & $8.100,30$ & $16.038,90$ & $28.679,30$ & 2,36 \\
\hline Frutas & $1.383,70$ & $1.470,80$ & $25.428,40$ & $60.335,90$ & $88.618,70$ & 7,29 \\
\hline $\begin{array}{l}\text { Olerícolas/ } \\
\text { Hortícolas, Flores } \\
\text { e Ornamentais, } \\
\text { Plantas Medicinais }\end{array}$ & 504,8 & $1.104,30$ & $14.317,80$ & $37.675,40$ & $53.602,30$ & 4,41 \\
\hline Café & 95,2 & 149,8 & $20.300,80$ & $4.888,60$ & $25.434,50$ & 2,09 \\
\hline Soja e Milho & 761,8 & $1.003,00$ & $11.800,10$ & $78.203,10$ & $91.768,00$ & 7,55 \\
\hline
\end{tabular}


138 - C\&T e I para a produção agropecuária brasileira: mensurando e qualificando gastos públicos

Tabela 2. Continuação.

\begin{tabular}{|c|c|c|c|c|c|c|}
\hline & ANF's & FAP's & IP's & Embrapa & TOTAL & $\begin{array}{c}\% \text { dos } \\
\text { Investimentos } \\
\text { totais }\end{array}$ \\
\hline Açúcar e Álcool & - & 558,1 & $5.822,20$ & 587,7 & $6.968,00$ & 0,57 \\
\hline Citros & 505,4 & $1.095,10$ & $6.152,90$ & 396,6 & $8.149,90$ & 0,67 \\
\hline Arroz & 90 & 39,7 & $4.434,80$ & $18.441,70$ & $22.986,20$ & 1,89 \\
\hline Algodão & 204,2 & 135,6 & $3.046,20$ & $22.731,00$ & $26.116,90$ & 2,15 \\
\hline Trigo & 41,4 & 136,4 & $1.923,40$ & $26.779,90$ & $28.881,10$ & 2,38 \\
\hline Papel e Celulose & 9,6 & 992,5 & 310,9 & - & $1.313,00$ & 0,11 \\
\hline Fumo & - & 28,9 & - & - & 28,9 & 0,00 \\
\hline Feijão & 18 & 207,8 & $2.956,00$ & $18.250,60$ & $21.432,40$ & 1,76 \\
\hline $\begin{array}{l}\text { Mandioca } \\
\text { e Inhame }\end{array}$ & 8,2 & 461,4 & $1.309,80$ & $14.997,90$ & $16.777,30$ & 1,38 \\
\hline Seringueira & - & 19 & 913,3 & - & 932,3 & 0,08 \\
\hline $\begin{array}{l}\text { Outros Produtos } \\
\text { Agrícolas }\end{array}$ & 77,2 & 602,1 & 955,8 & $8.467,70$ & $10.102,80$ & 0,83 \\
\hline $\begin{array}{l}\text { Agricultura } \\
\text { Orgânica }\end{array}$ & 41,5 & 405,5 & 419,7 & $4.378,10$ & $5.244,80$ & 0,43 \\
\hline $\begin{array}{l}\text { Sistemas } \\
\text { Agrosustentáveis } \\
\text { e Recursos } \\
\text { Ambientais }\end{array}$ & $1.425,00$ & $1.995,30$ & $28.758,40$ & $122.873,50$ & $155.052,10$ & 12,76 \\
\hline $\begin{array}{l}\text { Sistemas de } \\
\text { Produção e } \\
\text { Manejo de Solos }\end{array}$ & 274 & $1.897,80$ & $10.773,70$ & $83.786,00$ & $96.731,50$ & 7,96 \\
\hline Agrometeorologia & - & 226 & $9.352,50$ & $10.913,40$ & $20.491,90$ & 1,69 \\
\hline $\begin{array}{l}\text { Controle Biológico, } \\
\text { Fitopatologia e } \\
\text { Pragas }\end{array}$ & $2.215,30$ & $1.436,00$ & 521,5 & $62.411,60$ & $66.584,50$ & 5,48 \\
\hline $\begin{array}{l}\text { Biotecnologia e } \\
\text { Melhoramento } \\
\text { Genético }\end{array}$ & $3.547,80$ & 907,6 & 209,8 & $52.829,00$ & $57.494,30$ & 4,73 \\
\hline Outros & $1.190,40$ & $1.049,60$ & $22.817,60$ & $137.317,50$ & $162.375,10$ & 13,37 \\
\hline TOTAL & $33.644,40$ & $24.727,10$ & $224.081,10$ & $932.433,40$ & $1.214 .886,00$ & 100,00 \\
\hline
\end{tabular}

No caso da Embrapa, os maiores gastos da instituição em 2004 estavam voltados para o tema sustentabilidade, visto que $13,2 \%$ do seu orçamento foi direcionado às atividades relacionadas. Em seguida, a área de Sistemas de Produção e Manejo de Solos alcançou 9\% e as atividades vinculadas à produção de Soja e Milho representou 8,4\% dos gastos em 
C\&T e I. Em Outros, encontram-se os gastos que não se enquadravam em nenhuma outra subdivisão. Neste caso, os valores foram altos devido aos gastos dos centros Embrapa/SNT (Transferência de Tecnologia), Embrapa/SCT (Informação Tecnológica) e CNPTIA (Informática Agropecuária).

A Embrapa participa com a maior parte dos gastos por atividade agropecuária. Em alguns poucos casos isso não ocorre, como os gastos vinculados à cafeicultura, em que a Epamig-MG e o Incaper-ES possuem linhas de pesquisa importantes para essa cultura. $\mathrm{O}$ mesmo ocorre na cadeia de Açúcar e Álcool, em que os investimentos do Pesagro-RJ, principalmente, elevam a participação dos Institutos de Pesquisa nesta cadeia. Na citricultura, os maiores investidores em C\&T e I também são dos IP's, principalmente pela participação do Iapar-PR e do IAC-SP nas pesquisas do setor. Na cadeia de Seringueira, os gastos em pesquisa são praticamente todos $(98 \%)$ provenientes dos IP's. Apenas três institutos compõem estes investimentos: Epamig-MG, Empaer-MT e o Incaper-ES.

Por outro lado, no caso de Papel e Celulose e Fumo, as Fundações de Apoio à Pesquisa possuem maior participação nos investimentos. Para Papel e Celulose, a Fapesp é responsável por $98,2 \%$ dos gastos das FAP's e para o Fumo ela é a responsável por todos os investimentos em pesquisas neste setor, não somente dentro do agregado FAP's, como de todo os gastos públicos.

\subsection{Caracterização dos gastos do terceiro setor em C\&T e I para a produção agropecuária}

Em 2004, o total de investimentos em C\&T e I pelas instituições do terceiro setor analisadas neste estudo totalizaram $R$ \$ 64,357 milhões. Deste total, o Centro de Tecnologia Canavieira foi a principal instituição em volume de investimentos (38,7\%), seguida da Fundação Mato Grosso $(29,8 \%)$, do Instituto Riograndense de Arroz (15,6\%), da Cooperativa Central de Pesquisa Agrícola (10,3\%) e do Fundo de Defesa da Citricultura (5,6\%).

Os gastos das instituições sem fins lucrativos privilegiam as atividades produtivas mais representativas para o setor em que atuam ou representam. As atividades beneficiadas com estes recursos são, por ordem decrescente, a de Açúcar e Álcool, seguida de Soja e Milho, Arroz, Algodão, Citros e Trigo. A Tabela 3 traz uma análise da distribuição dos gastos em C\&T e I para cada atividades, de acordo com o a participação de cada agregado nestes gastos. 
Tabela 3. Porcentagem dos gastos do terceiro setor, segundo produtos das atividades agropecuária, 2004

\begin{tabular}{lcccccc}
\hline & Irga & CTC & Coodetec & Fundecitrus & $\begin{array}{c}\text { Fundação } \\
\text { Mato Grosso }\end{array}$ & TOTAL \\
\hline 11. Soja e Milho & $2,5 \%$ & - & $21,4 \%$ & - & $76,1 \%$ & $100,0 \%$ \\
12. Açúcar e Álcool & - & $100,0 \%$ & - & - & - & $100,0 \%$ \\
13. Citros & - & - & - & $100,0 \%$ & - & $100,0 \%$ \\
14. Arroz & $100,0 \%$ & - & - & - & - & $100,0 \%$ \\
15. Algodão & - & - & $23,9 \%$ & - & $76,1 \%$ & $100,0 \%$ \\
16. Trigo & - & - & $100,0 \%$ & - & - & $100,0 \%$ \\
\hline
\end{tabular}

Fonte: Resultados da pesquisa.

\section{Considerações finais}

A participação da Embrapa no desenvolvimento da C\&T e I para a produção agropecuária é predominante no Brasil. Em 2004, as atividades produtivas mais beneficiadas em termos de investimentos envolviam soja e milho, frutas, carne bovina e bubalinos, leite, Olerícolas/Hortícolas, Flores e Ornamentais, Plantas Medicinais e carne de frango.

As áreas que mais receberam investimentos públicos de pesquisa foram as de Sistemas Agrosustentáveis e Recursos Ambientais, Sistemas de Produção e Manejo de Solos, Controle Biológico, Fitopatologia e Pragas e Biotecnologia e Melhoramento Genético. Devido à importância destas áreas de pesquisa e atividades para a produção agropecuária brasileira, as mesmas tendem a continuar absorvendo a maior parte dos investimentos públicos em pesquisa. Para afirmar essa sentença, contudo, seria necessário fazer um estudo da série histórica dos investimentos em cada uma das atividades. Desta forma, seria possível analisar as cadeias em que o investimento em pesquisa pública tem decrescido ou aumentado.

No entanto, existem áreas e atividades agropecuárias em que os investimentos do setor público têm sido menos expressivos. Algumas atividades são importantes para a economia, como aquelas vinculadas à produção de Citros, Açúcar e Álcool e Papel e Celulose e, mesmo assim, tiveram menos de $1 \%$ dos investimentos do setor público. Algumas associações do terceiro setor (sem fins lucrativos) tentam minimizar esta deficiência, principalmente em Açúcar e Álcool e Citros. Estes setores, 
fortemente voltados para o comércio exterior, sempre investiram recursos próprios para o desenvolvimento de tecnologia.

Apesar de todo esforço dos autores, este trabalho, como é comum em pesquisas deste porte, possui algumas limitações. O objetivo de mensurar todos os gastos em C\&T e I para a produção agropecuária teve alguns obstáculos como a não-participação de alguns institutos públicos de pesquisa por motivos variados, o que prejudica a inferências dos resultados obtidos. Deve-se frisar, também, que este estudo analisa os gastos com C\&T e I de uma maneira estática. A realidade mostra que a inovação é um fenômeno complexo e dinâmico, no qual estão envolvidas muitas outras variáveis além daquelas mensuradas pelos indicadores aqui utilizados.

Certamente, este trabalho não pretendeu esgotar o assunto de uma área tão rica e com tão poucos estudos aplicados à realidade brasileira. Muitas outras áreas de investigação dentro do mesmo tema podem ser desenvolvidas. Sugerem-se estudos que incorporem outras atividades vinculadas à produção agropecuária, como o processamento e distribuição. Estudos que analisem gastos de uma forma menos estática, a partir de uma série histórica dos dados, de forma a analisar a dinâmica dos gastos para cada setor e cadeia, também seriam importantes.

\section{Referências Bibliográficas}

ANPEI. Como alavancar a inovação tecnológica nas empresas. Associação Nacional de Pesquisa, Desenvolvimento e Engenharia das Empresas Inovadoras, 2004.

ANPEI. Indicadores empresariais de inovação tecnológica: resultados da base de dados 2001. ANPEI, 2001.

BELL, M. e PAVITT, K. Technological accumulation and industrial growth: contrasts between developed and developing countries. Industrial and Corporate Change, v 2, n2, 1993

BEINTEMA, Nienke M.; ÁVILA, Antonio Flavio Dias; Pardey, Philip G. P\&D agropecuário no Brasil - Política, Investimentos e Perfil Institucional. Instituto Internacional De Pesquisas Sobre Políticas Alimentares. Fundo Regional de Tecnologia Agropecuária. Empresa Brasileira de Pesquisa Agropecuária. Washington D.C.: agosto 2001. 
CIS-2 Community innovation survey 2002/2003 (CIS 2002/2003). Eurostat, Statistical Office of the European Communities. Luxemburgo, 2004.

FINEP. Diretório da Pesquisa Privada. http://www.finep.gov.br/portaldpp, consultado em 12/12/2008.

MEYER-STAMER, Joerg. New Departures for Technology Policy in Brazil. Science and Public Policy, vol.22, n.5, p. 295-304, 1995.

MINISTÉRIO DA CIÊNCIA E TECNOLOGIA. Seminários Temáticos para a III Conferência Nacional de Ciência Tecnologia e Inovação. Edição Especial de Parcerias Estratégicas, n. 20 (pt. 4), p. 1157-1334. Brasília: CGEE, junho de 2005.

OCDE - Organização para a Cooperação e Desenvolvimento Econômico. The Measurement of scientific and technological activities: proposed guidelines for collecting and interpreting technological innovation data: Oslo manual. Paris: OECD, 1996.

PAVITT, K. Setoral patterns of technical change: towards a taxonomy and a theory. Research Policy, v. 13, p. 343-373, 1984.

POSSAS, Mario Luiz; SALLES-FILHO, Sergio; SILVEIRA, Jose Maria da. An evolutionary approach to technological innovation in agriculture: some preliminary remarks. Research Policy, vol. 25, 1996, p. 933-945.

PINTEC Pesquisa de Inovação Tecnológica. http://www.ibge.gov.br/home/estatistica/economia/industria/pintec/200 5/default.shtm e http://www.pintec.ibge.gov.br, consultada em 12/12/1008.

SCHUMPETER, J. A. (1912). A Teoria do Desenvolvimento Econômico 3a Ed., Ed Nova Cultural, São Paulo, 1988, 169p.

SCHUMPETER, J. A. (1943) O processo de destruição criadora. In:

Capitalismo, socialismo e democracia. Rio de Janeiro: Zahar, 1984. 


\section{ANEXO: Instituições participantes da pesquisa}

As agências de fomento CNPq e Finep, além da Embrapa, foram pesquisadas em âmbito nacional. Já quanto aos estados, as seguintes agências de fomento pesquisadas foram:

- Fundação de Amparo à Pesquisa do Estado de São Paulo (Fapesp).

- Fundação de Amparo à Pesquisa do Estado de Minas Gerais (Fapemig).

- Fundação Carlos Chagas Filho de Amparo à Pesquisa do Estado do RJ (Faperj).

- Instituto de Apoio à Pesquisa e ao Desenvolvimento Jones dos Santos Neves (Ipes).

- Fundação Araucária de Apoio ao Desenvolvimento Científico e Tecnológico do Paraná (Fundação Araucária).

- Fundação de Ciência e Tecnologia (Funcitec-SC).

- Fundação de Amparo à Pesquisa do Estado do Rio Grande do Sul (Fapergs).

- Fundação de Amparo à Ciência e Tecnologia do Estado de Pernambuco (Facepe).

- Fundação de Amparo à Pesquisa do Estado do Piauí (Fapepi-PI).

- Fundação de Amparo à Pesquisa do Estado da Paraíba (Fapep-PB).

- Fundação de Amparo à Pesquisa do Estado da Bahia (Fapesb-BA).

- Fundação de Amparo à Pesquisa do Estado de Sergipe (FAP-SE).

- Fundação de Amparo à Pesquisa e ao Desenvolvimento Científico e Tecnológico do Maranhão (Fapema-MA).

- Fundação de Amparo à Pesquisa do Estado de Mato Grosso (Fapemat).

- Fundação de Apoio à Pesquisa - UFG* (Funape-GO).

- Fundação de Apoio ao Desenvolvimento do Ensino Ciência e Tecnologia do Estado de Mato Grosso do Sul (Fundect-MS).

- Fundação de Amparo à Pesquisa do Distrito Federal (FAP-DF).

- Fundação de Amparo e Desenvolvimento da Pesquisa (Fadesp-PA).

- Fundação de Amparo à Pesquisa do Estado do Amazonas (Fapeam) 
Os seguintes Institutos Públicos de Pesquisa Agropecuária foram contatados:

(i): Na esfera federal: Embrapa que se constitui em 40 centros de pesquisa distribuídos por todo o território nacional.

(ii): Na esfera dos governos estaduais:

- São Paulo: Instituto Agronômico de Campinas (IAC), Instituto Biológico (IB), Instituto Zootécnico (IZ), Instituto de Tecnologia de Alimentos (Ital), Instituto de Economia Agrícola (IEA), além da Agência Paulista dos Agronegócios (Apta).

- Minas Gerais: Empresa de Pesquisa Agropecuária de Minas Gerais (Epamig).

- Rio de Janeiro: Empresa de Pesquisa Agropecuária do Estado do RJ (Pesagro-RIO).

- Espírito Santo: Instituto Capixaba de Pesquisa, Assistência Técnica e Extensão Rural (INCAPER).

- Paraná: Instituto Agronômico do Paraná (Iapar).

- Santa Catarina: Empresa de Pesquisa Agropecuária e Extensão Rural de SC (Epagri).

- Rio Grande do Sul: Fundação Estadual de Pesquisa Agropecuária (Fepagro).

- Pernambuco: Empresa Pernambucana de Pesquisa Agropecuária(IPA).

- Rio Grande do Norte: Empresa de Pesquisa Agropecuária do RN (Emparn).

- Bahia: Empresa Baiana de Desenvolvimento Agrícola S.A. (EBDA).

- Paraíba: Empresa Estadual de Pesquisa Agropecuária da Paraíba S.A. (Emepa).

- Sergipe: Empresa de Desenvolvimento Agropecuário do Sergipe (Emdagro).

- Mato Grosso: Empresa Mato-grossense de Pesquisa, Assistência e Extensão Rural (Empaer-MT).

- Goiás: Agência Goiânia de Desenvolvimento Rural e Fundiário (Agência Rural).

- Tocantins: Diretoria de Pesquisa Agropecuária e Desenvolvimento Rural - Fundação Universidade do Tocantins (Unitins AGRO).

- Mato Grosso do Sul: Instituto de Desenvolvimento Agrário, Pesquisa, Assistência Técnica e Extensão Rural do Mato Grosso do Sul (Idaterra) 
Além destes, foram também investigadas algumas instituições sem fins lucrativos que atuam na pesquisa agropecuária. Estas instituições são:

- Instituto Rio Grandense do Arroz (Irga).

- Fundo de Defesa da Citricultura (Fundecitrus).

- Centro de Tecnologia Coopersúcar (CTC - Copersucar).

- Cooperativa Central de Pesquisa Agrícola (Coodetec).

Vale ressaltar que outras instituições deste setor não foram contatadas por motivos variados, como:

- Coopersucar - afirmou que após a separação do CTC não atua mais em atividades de pesquisa, desenvolvimento e inovação tecnológica.

- Afubra (Associação dos Fumicultores do Brasil) - Não respondeu ao questionário por considerar que suas atividades não se enquadram como pesquisa agropecuária. 